\title{
Non-Hereditary Lesion
}

National Cancer Institute

\section{Source}

National Cancer Institute. Non-Hereditary Lesion. NCI Thesaurus. Code C53974.

A pathologic process that is not inherited in a familial pattern. 